\title{
Autorenregister Vol. 37,1997
}

Die Autoren der Abstracts der 'XV. Akademischen Tagung deutschsprechender Hochschullehrer in der Gynäkologie und Geburtshilfe' sind im entsprechenden Autorenregister in Vol. 37, Nr. 2, 1997 (S. 213/214) aufgelistet.

(B) = Buchbesprechung

Abendstein, B. 41 Aigner, M. 203 Arzt,W. 203

Backe,J. 30 Beard, R. 75 Berghold,A. 25 Bollmann,R. 130 Bonkhoff,H. 216 Borruto, F. 44,48

Brenner, E. 41 Brezinka, Ch. 119

Chaoui,R. 130 Concin, H. 227

Denk,W. 169 De Wilde, R.L. 5 Dieterich, H. 230 Duc,G. 226(B)

Fasching, G. 25 Fechter, M. 25 Fistarol, M. 44, 48 Fox,H. 171 Friedrich, M. 216 Fuith,L. 227

Geraedts, M. 14 Gerstner, G.J. 169 Glatzel,E. 130 Grammer, K. 150 Gruber,W. 71 Gruböck,K. 221

Haas, J. 21 Haller,U. 117,209 Hasbargen, U. 143 Häusler, M.C.H. 25 Heider, R. 62 Henckel von Donnersmark, G. Hepp,H. 54, 117, 143 Hesseling, M. 5 Hillemanns, P. 179 Höfler,G. 68 Fluber,J.C. 39 Husslein,P. 1,71 Hüttner, U. 21

Jirecek, S. 39 Jütte, A. 150

Kaider,A. 221 Kainer, F. 21 Kimmig,R. 179 Kiss,H. 39 Klingler,P. 41 Knappitsch, G. 221

Konecny, G. 54 Kronberger, L. 68 Kurz,Ch. 221

Lahousen, M. 227 Lechner, Th. 119 Lehner, R. 39 Leodolter, S. 227 Loidl,K. 62

169

Mayr,J. 25 Missliwetz, J.

209

Pastorelli, G. Petru, E. 68 Pollak,A. 71

Reinold,E. 74,117 Reus,W.A. 154 Roemer, V.M. 161 (B), 191 Rudelstorfer, B. 62 143

Salzer,H. 177,221,227 Schmidt, W. 216 Schneider, H. 53 Schöndorf, N.K. 136 Schröck,A. 172 Schröter,B. 130 Schulte,F.J. 162 Selbmann, H.-K. 14 Sevelda,P. 221 Smola,M. 68 Speiser, P. 221 Starz,I. 68 Steiner,R. 209 Stephan,K. 119 Strauss, A. 143 Stummvoll,W. 227

Taus,P. 68 Tews, G. 203 Thaler, C. 179 Tscharf,J. 41

Untch,M. 54

Vavra,N. 221 Villena-Heinsen, C. 216

Weiss, P.A.M. 21 Wenzl,R. 39

Westerburg, B. 143 Winter, R. 52,73,227

Yaman,C. 203

Zotter, H. 25

\section{KARGEÍl}

E-Mail karger@karger.ch Fax+ 41613061234 http:// www. karger. ch (C) 1998 S. KargerAG, Basel 
This article is also accessible online at: http:// BioMedNet.com/ karger 237 